\title{
Niche regulation of corneal epithelial stem cells at the limbus
}

\author{
Wei $\mathrm{Li}^{1}$, Yasutaka Hayashida ${ }^{1}$, Ying-Ting $\mathrm{Chen}^{1}$, Scheffer CG Tseng ${ }^{1}$ \\ ${ }^{1}$ Ocular Surface Center and TissueTech Inc. Miami, Florida, 33173, USA
}

Among all adult somatic stem cells, those of the corneal epithelium are unique in their exclusive location in a defined limbal structure termed Palisades of Vogt. As a result, surgical engraftment of limbal epithelial stem cells with or without ex vivo expansion has long been practiced to restore sights in patients inflicted with limbal stem cell deficiency. Nevertheless, compared to other stem cell examples, relatively little is known about the limbal niche, which is believed to play a pivotal role in regulating self-renewal and fate decision of limbal epithelial stem cells. This review summarizes relevant literature and formulates several key questions to guide future research into better understanding of the pathogenesis of limbal stem cell deficiency and further improvement of the tissue engineering of the corneal epithelium by focusing on the limbal niche.

Cell Research (2007) 17:26-36. doi:10.1038/sj.cr.7310137; published online 9 January 2007

Keywords: corneal epithelium, stem cell, niche

\section{Introduction}

Unlike the rest of the body surface, the ocular surface is designed to be wettable so as to maintain comfort while providing a smooth optical surface. On the ocular surface, the cornea is most unique in being both avascular and transparent so as to allow the light to be transmitted to the retina. Therefore, in order for us to enjoy seeing the outside beautiful world, the corneal epithelium needs to withstand constant attrition caused by exposure-induced dryness and potential light-induced damage.

To cope with the aforementioned demand, one fundamental strategy resorts to prolonged, if not indefinite, selfrenewal of the corneal epithelium. This unique property is governed by corneal epithelial stem cells (SCs), of which the location was discovered by the laboratory of Dr TungTien Sun 20 years ago to be exclusively in the basal layer of the limbus, i.e., the outer vascular rim at the junction between the cornea and the conjunctiva [1]. This important discovery has helped resolve the mystery of "conjunctival

Correspondence: Scheffer C G Tseng

Ocular Surface Center, 7000 SW 97 Avenue, Suite 213, Miami, FL 33173, USA.

Tel: 1-305-274-1299; Fax: 1-305-274-1297

E-mail: stseng@ocularsurface.com transdifferentiation" thought to take place in the event of a total corneal epithelial loss [2], explained why a number of corneal blinding diseases manifest limbal SC deficiency with cytological evidence of conjunctivalization [3], and devised a new surgical procedure of transplanting the SCcontaining limbal epithelium for treating eyes inflicted with limbal SC deficiency [4].

A number of studies have since disclosed that limbal SCs share some features common to other adult somatic SCs. For example, limbal SCs have the smallest cell size [5], are slow-cycling and hence label-retaining [6], and do not express markers destined for terminal differentiation such as cytokeratins 3 [1] and 12 [7-9], involucrin [10], and connexin 43 [11]. In contrast, the SC-containing limbal epithelium has a high proliferative potential in different cultures [12-15], and their in vitro proliferation is resistant to the inhibition by tumor-promoting phorbol esters [13, $16,17]$. Furthermore, limbal basal epithelial cells express cytokeratin 19 [18], and integrin $\alpha 9$ [10, 19], and preferentially express such progenitor markers as p63 [20], especially its $\Delta \mathrm{Np} 63 \alpha$ isoform [21, 22], Bcrp1/ABCG2 [10, 23-25], and N-cadherin [26].

Compared to other types of adult somatic SCs, limbal epithelial SCs are unique in being enriched in an anatomic location that is relatively easy to access, hence rendering it an attractive model to investigate the underlying regula- 


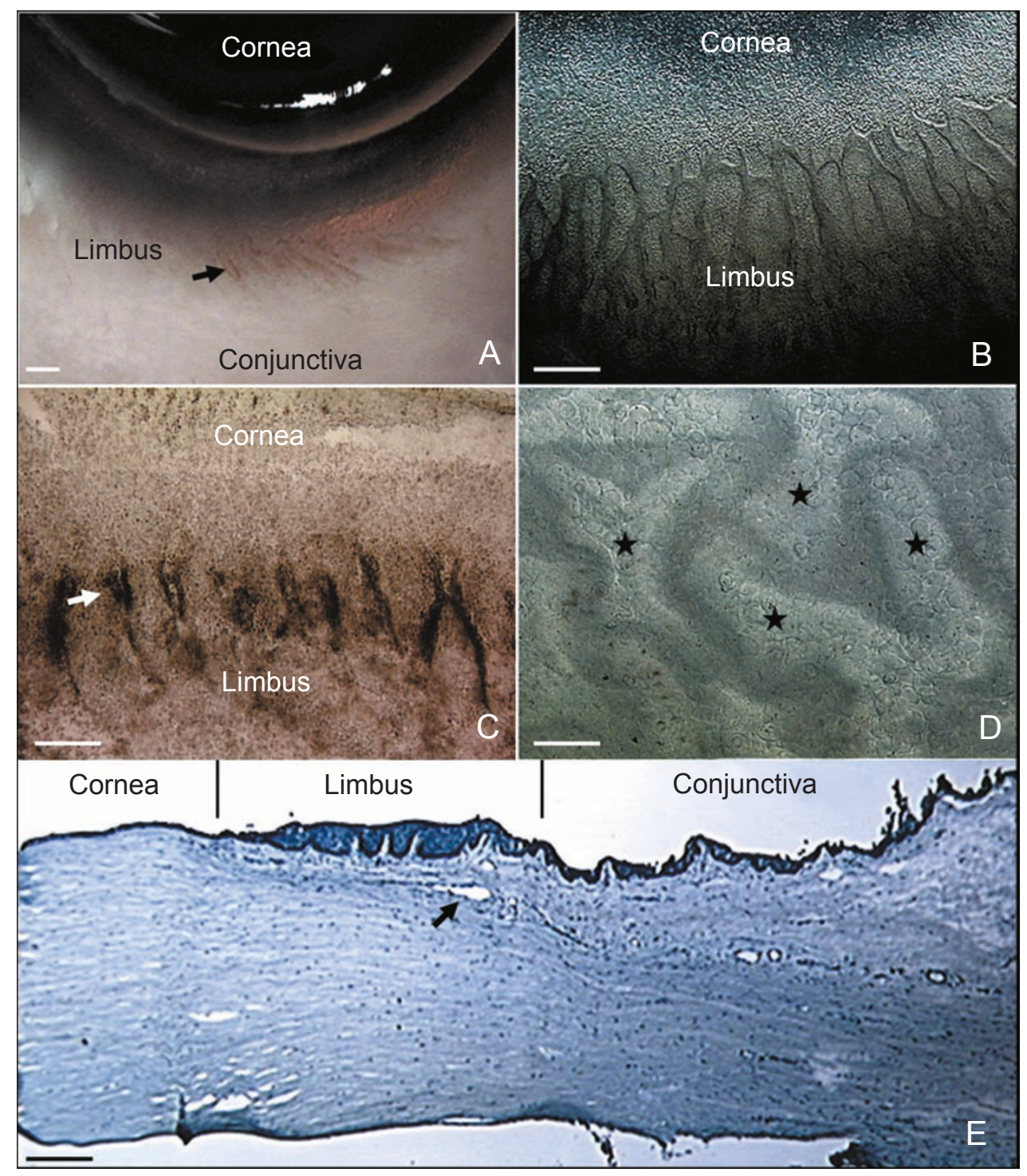

Figure 1 The limbal palisades of Vogt. Palisades of Vogt (arrow) are readily recognized in the human limbus (A). Such a unique pigmented structure can be identified on the flat mount preparation of Dispase-isolated human limbal epithelial sheets (B). In donors with a darker skin, these palisades of Vogt are pigmented (C, arrow). Under higher magnification, these limbal areas show undulated epithelial papillae (D, stars). Hematoxyline staining highlights higher stratification and more undulation of the limbal epithelium, and the underlying limbal stroma has high cellularity and vascularity (E, arrow shows blood vessel). (Bar represents $500 \mu \mathrm{m}$ in $\mathbf{A}$ and $\mathbf{B}, 200 \mu \mathrm{m}$ in $\mathbf{C}$ and $\mathbf{E}$, and $50 \mu \mathrm{m}$ in $\mathbf{D})(\mathrm{A}, \mathrm{B},[127])$

tory mechanism. The same reason has made it possible to perform several surgical procedures to engraft both autologous and allogeneic limbal epithelial SCs to restore sight in animal [27-29] and human [4, 30-32] limbal-deficient corneas. Furthermore, several new surgical approaches based on transplantation of ex vivo expanded limbal epithelial SCs have also been attempted [33, 34]. These new advances collectively make the corneal/limbal epithelia a prime tissue to practice regenerative medicine. For more detailed information on the aforementioned progresses regarding limbal epithelial SCs, the reader is encouraged to consult several reviews [35-45]. Further understanding of how self-renewal and fate decision of limbal epithelial SCs are regulated will undoubtedly unravel their additional therapeutic potentials in the future.

Increasing evidence supports that adult germ and somatic SCs are regulated by their niche, i.e., a special microenvironment consisting of other cellular and extracellular 


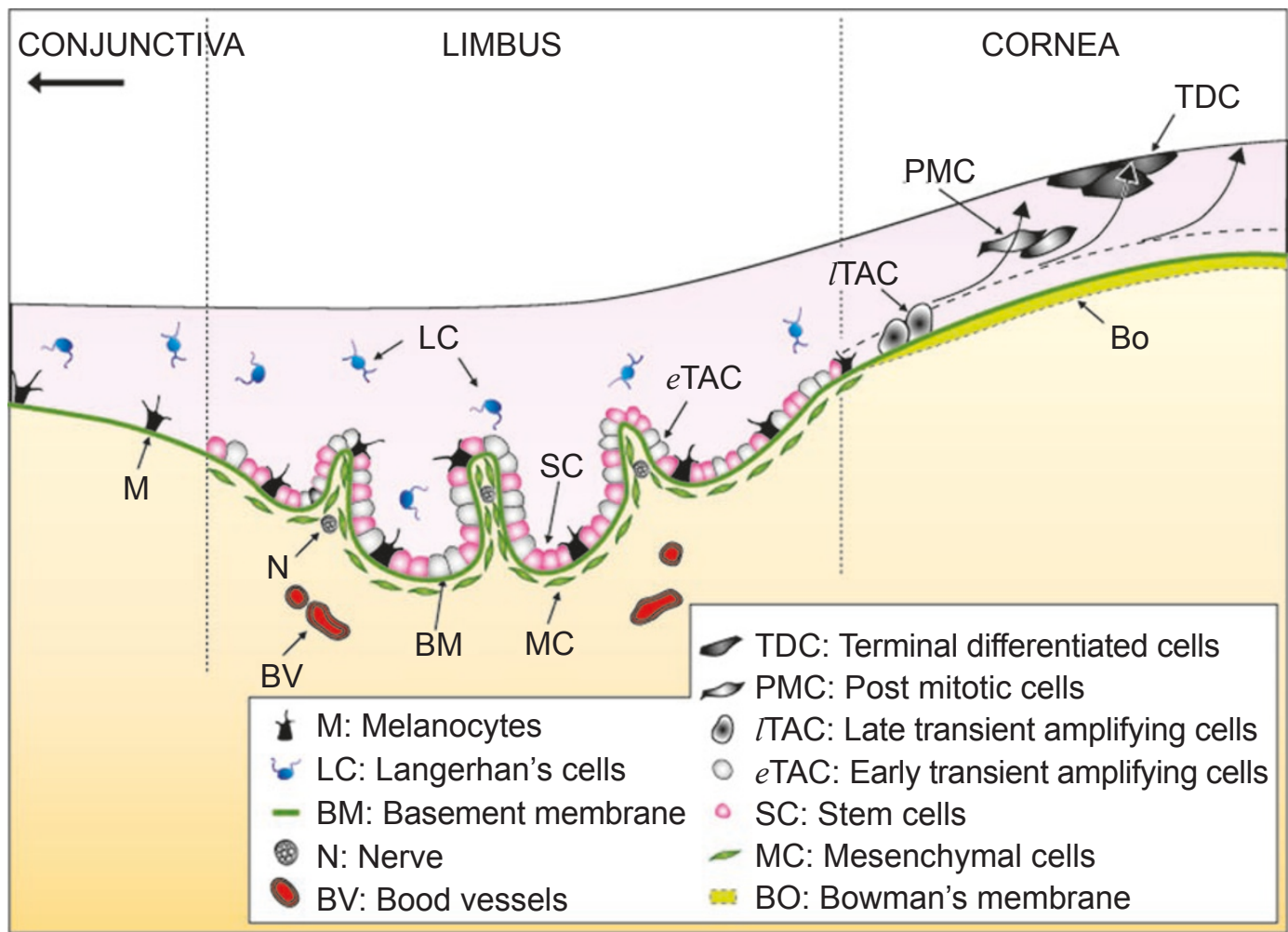

Figure 2 Hypothetical scheme of limbal stem cell niche. Limbal epithelial stem cells (SC) are located at the limbal basal layer. In this epithelial level, there are several other cell types in the vicinity such as the immediate progeny, i.e., early transient amplifying cells ( $e$ TAC), melanocytes (M), and Langerhan's cells (LC). It remains to be determined whether these cell types act as niche cells. It is believed that eTAC will be destined for progeny production by differentiating into late TACs (lTAC) located at the corneal basal layer, then into suprabasal post-mitotic cells (PMC), and finally into superficial terminally differentiated cells (TDC). The limbal basement membrane (BM) separating the epithelium from the underlying stroma has several unique components. The subjacent limbal stroma contains mesenchymal cells (MC), which may also serve as niche cells. Because the limbal stroma is highly innervated and vascularized, the respective role of nerves $(\mathrm{N})$ and blood vessels $(\mathrm{BV})$ in the niche remains to be defined.

components in the vicinity (for reviews see [46-48]). Therefore, similar to what has been carried out in other types of SCs, one important way of exploring the biological regulation of limbal SCs is to understand how they are regulated by their niche. This review intends to summarize the current status regarding how much we know about the limbal niche. We would like to raise several key questions that may fill in the missing gaps regarding how the limbal niche might regulate limbal epithleial SC's self-renewal and fate decision. Under each question, we also discuss areas that await future research.

\section{Where is the limbal stem cell niche?}

The SC niche has both anatomic and functional dimensions. Before functional dimension can be addressed, it is necessary to understand where the limbal niche is. Ana- tomically, the limbal SC niche is located at the Palisades of Vogt (Figure 1), which is highly pigmented because of melanocytes [49-51], and is infiltrated with antigen-presenting Langerhan's cells [52] and suppressor T-lymphocytes [53]. Unlike that of the cornea, the basement membrane of the limbus is undulating with papillae or 'pegs' of stroma extending upward [54] and fenestrated [55, 56]; these anatomic features in the limbus suggest that limbal epithelial SCs might closely interact with cells in the underlying limbal stroma (Figure 2). The preferential expression of $\alpha 9$ integrin [19] and N-cadherin [26] without connexin 43 [11] also suggests that limbal SCs interact with unique extracellular components in the niche. Compositionally, other than laminin-1 and laminin-5, the limbal basement membrane also expresses laminin $\alpha 2 \beta 2$ chains, while the corneal basement membrane does not. Moreover, $\alpha 1, \alpha 2$, and $\alpha 5$ chains of type IV collagen are present in the limbal 
basement membrane, while $\alpha 3$ and $\alpha 5$ chains are in the corneal counterpart $[57,58]$. These limbal basement membrane components might help determine SC distribution in the niche as suggested in the intestinal crypt villus (for review, see [59]). Furthermore, like that of other SC niches [60, 61], the limbal basement membrane might help sequester and hence modulate concentrations of growth factors and cytokines that are released from limbal niche cells for efficient and precise targeting onto limbal SCs.

Underneath the basement membrane, the limbal stroma is heavily innervated [62] and vascularized [63] (Figure 1). Cells residing in the limbal stroma are heterogenous and yet poorly defined. Besides resident mesenchymal cells, one cannot ignore the contribution of bone marrow-derived cells migrating into the limbal stroma [64]. The physical closeness between limbal epithelial SCs and their underlying or surrounding "niche cells" has not been demonstrated, nor has the dependence of limbal SC functions on such close interactions.

By definition, niche cells provide a sheltering environment that shields SCs from stimuli that may adversely promote differentiation and apoptosis, threatening SC reserves [47]. In this regard, melanocytes, distributed in the limbal basal layer with their cellular projections extending to surrounding basal epithelial cells [51], may be one candidate of niche cells (Figure 2). These cells produce and transport melanin pigments into epithelial cells so as to minimize damage caused by ultraviolet irradiation, a presumed action similarly described in the SC-containing bulge area of the human skin [65]. Little is known about the molecular mechanism explaining cytokine dialogues operating between melanocytes and limbal SCs, let alone between those of other cells in the vicinity.

\section{Is there any evidence suggesting niche regulation of limbal epithelial SCs?}

It is generally accepted that the differentiation of lineagecommitted SCs into mature progenies is a one-way biological process. When rabbit limbocorneal explants were cultivated at an air-fluid interface, epithelial proliferation and stratification is promoted [66]. In this model, intrastromal invasion of basal progenitor cells occurs only in the limbal, but not the corneal region [67]. Such intrastromal invasion of limbal basal epithelial progenitor cells only occurs when the limbal epithelial tissue is recombined with the live, but not devitalized, limbal stroma, and is abolished when recombined with the live corneal stroma [67]. When the corneal epithelial tissue is recombined with the live limbal stroma, there is no intrastromal invasion [67] whereas the basal epithelial cells lose expression of cytokeratin 3 and connexin 43 , indicative of de-differentiation of corneal transient amplifying cells (TACs) [66]. Conversely, when the limbal epithelial tissue is recombined with the live corneal stroma, basal epithelial cells express cytokeratin 3 and connexin 43, indicative of terminal differentiation [66]. Collectively, these findings strengthen the notion that the limbal stromal microenvironment indeed plays an important role in down-regulating epithelial differentiation, and that limbal stroma may contain niche cells to promote the SC phenotype. Furthermore, they also indicate that the insult of air-exposure is sufficient to alter the limbal niche to promote intrastromal invasion of limbal basal progenitors via epithelial-mesenchymal transition (EMT) [67]. Future studies of the underlying molecular mechanism may help unravel whether and how limbal mesenchymal cells may serve as potential niche cells to modulate limbal SCs.

Remarkably, well-differentiated adult corneal TACs can also be reprogrammed to de-differentiate into epidermal tissues in response to embryonic dermal stimuli $[68,69]$. Such trans-differentiation occurs in a multiple-step process first involving translocation of PAX6 from the corneal epithelial nucleus to the cytoplasm and then its complete repression [70]. Subsequently, some critical signals in the Wnt pathway including $\beta$-catenin and Lef- 1 are upregulated. Finally, the corneal cytokeratin pair 12 and 3 is replaced by skin cytokeratins 5,14 , and 17 . The development of pilosebaceous and sweat glands further implies that corneal-derived hair follicles contain a source of multipotent cells similar to those usually found in the bulge region of the skin. The fact that the embryonic dermal niche can turn corneal TACs into multipotent skin precursors provides strong evidence supporting the notion that the underlying stromal niche of each tissue is unique and is a potent modulator of the plasticity of not only SCs but also TACs.

\section{How can limbal epithelial SCs and their niche cells be identified?}

The first step to study the limbal niche is to identify where limbal epithelial SCs exactly lie before one can trace its vicinity with accuracy. One common method to identify limbal epithelial SCs is to label them according to their slow cell cycle [6]. Using this method, epidermal [71] and cardiac [72] niches have been identified. No study has been conducted in the same manner to identify the cellular components of the limbal niche. The other method to identify limbal epithelial SCs is based on their expressed markers. Although limbal epithelial SCs preferentially express several markers (see above), unfortunately there is no consensus bona fide marker [44, 45]. It is highly plausible that limbal epithelial SCs may express a set of genes as their "signature" rather than a single one, similar to what has been found for epidermal keratinocyte SCs [71, 
73]. Both the label-retaining pattern and immunostaining patterns of several putative markers have revealed that not all basal cells are SCs (for review see [44]), a finding consistent with the notion that true SCs represent only a small fraction in a given tissue [74]. Taken together, the heterogeneity of limbal basal cells also suggests that limbal SCs are physically in close contact with their immediate progeny, i.e., TACs. It remains to be elucidated whether TACs in the limbus differs from those located in the corneal basal layer based on the stage of differentiation into early vs. late TACs, respectively (Figure 2). It also remains to be determined whether limbal TACs, like those in the cardiac niche [72], may play a role in instructing the SC fate in the niche. Intriguingly, some limbal basal cells also express vimentin $[18,44]$, a mesenchymal cell marker. Because both Langerhan's cells and melanocytes that reside in the limbal basal layer also express vimentin, future studies are needed to determine whether limbal epithelial SCs also express vimentin or instead these vimentin-expressing cells actually represent niche cells. Clarification of these questions may help identify limbal niche cells and their interactions with limbal epithelial SCs.

\section{How can limbal epithelial SCs and their niche cells be isolated?}

Once the limbal niche is identified, the next obvious step is to isolate it from the in vivo habitat so that cells in the niche can be further investigated. To this end, intact limbal epithelial sheets can be successfully isolated by digestion with Dispase from several species $[66,75,76]$. Single cells rendered by a brief treatment with trypsin and EDTA of such isolated limbal epithelial sheets have been used by many investigators as the primary source of limbal epithelial SCs for subsequent manipulations including fluorescent-activated cell sorting (FACS) and culturing. It remains unknown whether different protocols of Dispase digestion actually remove the entire limbal epithelial SCs, niche cells or both. This concern is raised because a recent study showed that there are invading "crypt-like" structures in human limbal palisades of Vogt [55]. Furthermore, this concern is justified because as described above limbal basal progenitor cells can invade into the limbal stroma [67]. If indeed both limbal SCs and their niche cells were completely removed from the in vivo habitat by Dispase digestion, it remains unknown whether subsequent tryp$\sin$ /EDTA treatment might disrupt their intrinsic intercellular connections, and whether such disruption might then affect the success of subsequent cultivation/expansion. If however only limbal SCs were isolated, there has not been any attempt made to isolate niche cells from the remaining limbal stroma.
Based on the principle that many adult somatic SCs preferentially express Bcrp1/ABCG2, a member of ATPbinding cassette transporters, they can be isolated as the side population (SP) using FACS via the unique property of effluxing Hoechst 33342 dye [77, 78] (for review see [79]). Using this method, SP cells have been isolated from human [23-25], rat [80], and rabbit [24, 81, 82] limbal tissues. The frequency of SP cells from the freshly isolated limbal epithelium varied from $0.2 \%$ to $0.64 \%$ in humans and from $0.4 \%$ to $1.21 \%$ in rabbits, while no SP cells were detected in human and rabbit central corneas. Interestingly, a recent study showed that $4.6 \%$ of SP cells are isolated from the rat central corneal epithelium, which is significantly higher than $0.4 \%$ from the rat limbus [80]. Future studies are needed to determine whether ABCG2 is expressed not only in the limbal tissue, whether other members of $\mathrm{ABC}$ transporter family may be expressed by some corneal cells, and whether cells other than SCs can also express ABCG2. Although epidermal SP cells have been proven devoid of melanocytes or dendritic cells [83], a preliminary study did show that both human and rabbit limbal SP cells contain non-epithelial cells such as lymphocytes [84], raising the question whether it is valid to use SP as a source of limbal SCs.

\section{Will restoration of niche support be critical for $e x$ vivo expansion of limbal epithelial SCs?}

In as much as it remains uncertain whether the success of aforementioned isolation might be hampered by intrinsic disruption of intercellular interaction/support between SCs and niche cells, much evidence does suggest that restoration of such support is crucial for ex vivo expansion of limbal epithelial SCs. In fact, many types of adult somatic SCs have limited functions when detached from their in vivo niche. To circumvent this problem, one common approach is to cultivate them on a feeder layer made primarily of growth-arrested mesenchymal cells as a surrogate niche. For many types of epithelial progenitor cells, ex vivo expansion resorts to co-culturing on $\beta$-irradiated or mitomycin $\mathrm{C}$-treated murine $3 \mathrm{~T} 3$ fibroblast feeder layers first pioneered by Rheinwald and Green in 1975 [85].

Interestingly, using the clonal culture system based on 3 T3 fibroblast feeder layers, SP cells generate much less colonies than non-SP cells in freshly isolated limbal epithelial cells from both human [24] and rabbit [24, 81, 82]. These results prompt one to suspect whether expression of ABCG2 is a salient feature of limbal SCs as discussed above. Nevertheless, SP cells from freshly isolated rabbit limbal epithelial sheets showed a five-fold increase of colonies after corneal epithelial wounding to activate limbal SCs [82]. Furthermore, SP cells harvested from primary 
human limbal epithelial cultures yield more colonies than those of non-SP cells [25]. A similar finding was also noted in cultured epidermal keratinocytes [86]. These results suggest that clonal expansion of "quiescent" limbal SCs is less apt on 3T3 fibroblast feeder layers than "activated" limbal SCs, which generate sufficient numbers of TACs. Alternatively, clonal expansion of limbal SCs may require additional support from TACs that is absent on 3T3 fibroblast feeder layers.

Another method is to use amniotic membrane as an ex vivo surrogate to expand limbal epithelial SCs in culture [87-89]. This novel approach was derived from the clinical experiences in transplanting cryopreserved human amniotic membrane, i.e., the innermost layer of the placenta, to facilitate ocular surface reconstruction (for reviews see [90-94]). Many diverse action mechanisms have been ascribed to the amniotic membrane for its supplanting with a new basement membrane and a stroma that can suppress inflammation, scarring and angiogenesis (for review see [95]). Importantly, amniotic membrane transplantation alone is sufficient to restore the normal corneal epithelial phenotype in human corneas with partial limbal SC deficiency [96-98], indicating that amniotic membrane helps expand residual limbal epithelial SCs in vivo. The above clinical discovery has led others to successfully transplant such an ex vivo expanded human limbal epithelial tissue to treat human corneas with total limbal SC deficiency [34, 99, 100]. Because no murine 3 T3 fibroblast feeder layer is needed, human amniotic membrane may serve as an $e x$ vivo surrogate niche (for review see [39]). Because the resultant epithelial phenotype is "limbal" when expanded on an intact amniotic membrane, which retains the devitalized amniotic epithelial cells, but is "corneal" when expanded on an epithelially-denuded amniotic membrane [101], we began to explore the idea that human amniotic epithelial cells may serve as a better non-xenogenic surrogate niche to support limbal epithelial SCs [Chen et al, manuscript submitted, 2006]. Continuous search for the most ideal candidate of ex vivo niche cells is important to allow us to expand limbal epithelial SCs effectively for further manipulations.

The finding that amniotic membrane transplantation can treat partial limbal SC deficiency also indicates that amniotic membrane may not only mobilize limbal SCs from the adjacent normal limbal tissue, but also recruit some multipotent progenitors from such a remote location as the bone marrow. The latter hypothetical scenario, if proven, illustrates an exciting new possibility for the limbal niche in directing trafficking and homing of host circulating SCs, an emerging concept well documented in the hematopoietic niche (for review, see [102]), and the Drosophila germline niche [103].

\section{Can damaged limbal niche cause limbal SC defi- ciency?}

As stated above, limbal SC deficiency is commonly manifested in many blinding ocular surface diseases. Besides the hallmark of conjunctivalization, i.e., ingrowth of conjunctival epithelial cells, the limbal-deficient corneas also show chronic inflammation, vascularization and scarring (for reviews see [41, 104]). When the cytological evidence of conjunctivalization is used as a clinical tool for diagnosing limbal SC deficiency [3], these diseases can further be subdivided into two major categories [41]. The first category is characterized by the destructive loss of limbal SCs by chemical/thermal burns, Stevens-Johnson syndrome, multiple surgeries, extensive microbial infection, radiation, and anti-metabolite uses. Intriguingly, diseases in the second category do not have such a destructive loss, and yet with time, also manifest the same phenotype of limbal SC deficiency. One prototypic disease in the second category turns out to be aniridia (due to allele mutation of PAX 6). Heterozygous Pax 6null mice (small eye) also show the pathologic features of limbal SC deficiency [105]. It has been speculated that the limbal niche is dysfunctional in these mouse limbal deficient corneas (for review see [106]). Investigation into the molecular mechanism of how PAX 6 controls the limbal niche is vital (also see below).

Besides aniridia, other causes in the second category include multiple endocrine deficiencies and diverse diseases affecting the peripheral cornea and the limbus of which the common denominator is chronic inflammation in the limbal stroma. Indeed, intensive inflammatory cell infiltration was found in corneal and limbal pannus specimens from patients with total limbal SC deficiency [107]. Furthermore, chronic inflammation threatens the well-being of transplanted limbal autograft [28]. One pathogenic insight into how inflammation may lead to limbal SC deficiency is learned from a recent study showing how limbal basal epithelial progenitor cells may invade into the limbal stroma through the process of EMT when rabbit limbal explants are cultured at the air-fluid interface [67]. This process has been reproduced in human limbal explants when cultured on intact amniotic membrane, a technique as mentioned above used for ex vivo expansion of limbal epithelial SCs [108], disclosing one drawback of this protocol to be progressive decline of limbal epithelial progenitor cells migrating onto the amniotic membrane. Because trans-differentiation of epithelial cells to fibroblasts via EMT has been implicated in the pathogenesis of renal and lung fibrosis (for review see [109]), the above findings also help explain why limbal SCs are lost during fibrosis in limbal SC deficiency. Because the above pathologic process 
only occurs in limbal basal epithelial progenitor cells when there is live limbal stroma [67], future studies are needed to determine what kinds of damage to the limbal niche by chronic inflammation might trigger limbal SC deficiency. If proven, besides transplantation of limbal SCs, restoration of a healthy limbal niche would be a new strategy for treating limbal SC deficiency.

\section{When and how does limbal stem cell niche form dur- ing morphogenesis?}

It is well known that the corneal epithelium is derived from the surface ectoderm while the mesenchymal cells of the anterior eye segment predominately originate from the neural crest. During eye morphogenesis, there is intensive interaction between epithelial and mesenchymal cells to precisely control their proliferation, migration, and differentiation. There are two waves of mesenchymal cell migration involved in the anterior eye development; the first wave cells form the corneal endothelium and stromal keratocytes, and the second differentiates into the trabecular meshwork, the iris stroma and the ciliary body (for review see [110]). Much is to be learned concerning when mesenchymal cells reach the limbal area and how they are destined to form the limbal niche.

Serial morphogenic events in embryogenesis are controlled by different transcription factors. The earliest transcription factor expressed when embryonic SCs are destined to the keratinocyte lineage is p63 [111]. However, the first recognized ectodermal gene expression associated with eye development is PAX 6 [112], which is consistently turned on by the ocular surface epithelium postnatally [113]. In contrast, head surface ectodermal cells lacking PAX 6 expression continue a "default differentiation pathway" to generate the epidermis. Several transcription factors such as MAF [114], FOXE3 [115] and PITX3 [116] might be involved in guiding early differentiation of the ocular mesenchyme because dysfunction of these transcription factors can cause Peter's anomaly, of which some may also manifest limbal SC deficiency, a hallmark found in aniridia.

Nevertheless, the full maturation of the limbal niche might extend into the postnatal life. This notion is suggested in the mouse or rat corneal epithelium where some corneal basal epithelial cells still retain SC function postnatally before SCs become sequestered to the limbal area [74, 117-119]. Therefore, if these findings hold well not just for rodents but also humans, future studies are needed to determine whether postnatal stimuli such as eye opening and exposure to the air via the tear film play a role in facilitating the maturation of the limbal SC niche.

\section{What signaling pathways are involved in the niche control of limbal SCs?}

SCs need to be communicating with their own niche to maintain their self-renewal and fate decision in generating the progeny. This SC-niche cross-talk may involve cell-cell contact, cell-matrix contact, as well as paracrine factors and their receptors. Different studies have shown that signals such as the Sonic hedgehog (Shh) pathway, Wnt/ $\beta$-catenin pathway, Notch pathway, and TGF- $\beta$ /BMP pathway play important roles in the niche control of different types of SCs (for review, see [48]). However, little is known about the cross-talk between limbal SCs and their niche. Recently, mouse null for expression of the Dickkopf (Dkk) family number Dkk2, one of the Wnt pathway inhibitors, was shown to lose the corneal fate decision on the ocular surface to epidermal differentiation [120]. As a result, Wnt/ $\beta$-catenin pathway is upregulated in the limbal, but not corneal, mesenchyme, indicating that Dkk2 acts by inhibiting Wnt signaling in the limbal stroma [120], providing the first evidence for a limbal mesenchymal (niche) role in limbal SC differentiation during morphogenesis. Because expression of PAX 6 is lost in the Dkk2-null corneal epithelium, it is likely that Dkk2 might be an upstream regulator dictating PAX 6 expression in the ocular surface epithelium. Further investigation into this molecular control may not only unravel how the limbal niche is developed but also shed light on how the limbal niche becomes dysfunctional in aniridia. Conditional inactivation of Notch 1 in adult mice induces hyperplasia and keratinization of the corneal epithelium with activation of $\beta$-catenin pathway, mimicking epidermal differentiation [121]. However, it remains unknown whether the limbal niche is altered when epithelial expression of Notch 1 is interfered. Besides dysgenesis of the trabecular meshwork and Schlemm's canal drainage structures, peripheral corneal scarring and vascularization was seen in mice with heterozygous deficiency of BMP4 [122]. It would be interesting to know whether the corneal abnormality is due to dysfunction of limbal niche. Another mesenchymal cell derived mitogen for epithelial cells is keratinocyte growth factor (KGF, or FGF-7). Transgenic mice with epithelial overexpression of human KGF leads to hyperproliferation of embryonic corneal epithelial cells, and their subsequent differentiation into functional lacrimal gland-like tissues without K12 keratin expression [123]. This result suggests that the limbal niche is no longer functional in guiding the corneal epithelial differentiation when these cells overexpress KGF. It remains to be determined whether the effect of this cytokine perturbation on limbal niche control of limbal SC behavior is temporally and spatially dependent. 


\section{Can limbal epithelial SCs be multipotent when the niche is modified?}

Traditionally, cell commitment has been viewed as a series of irreversible steps, involving an increase of commitment to a particular cell lineage and a loss of the capability to differentiate to all others. Therefore, the lack of such commitment by enhanced SC plasticity may lead to "trans-differentiation" and serves as a mechanism to explain how adult tissue-specific SCs could potentially generate other organs' cells [124].

Because limbal epithelial SCs may undergo EMT to become fibroblasts when the limbal niche is damaged, one may speculate that limbal epithelial SCs are not restricted only to differentiation toward the corneal epithelial lineage. Because plasticity leading to de-differentiation and then transdifferentiation into the epidermis can happen even in corneal TACs when engrafted to the embryonic dermis $[69,70]$, one may further speculate that limbal epithelial SCs might be multipotent if an appropriate stromal niche is provided. Such a hypothesis is supported by the findings that neural differentiation of the limbal epithelium takes place when heterotopically transplanted into the mouse hippocampus [125], and that ectodermally derived limbal SCs display neuronal electrophysiology and gradually express the neural SC marker nestin when removed from the limbal niche to an in vitro environment [126]. Although SC plasticity might be altered by culturing conditions, clarification of whether indeed limbal SCs possess multipotency is an important issue. Answers addressed to the aforementioned questions will also help us enhance limbal SCs' plasticity to reveal their multipotency. If such multipotent SCs can be isolated and the instructive signal from the limbal niche be identified, an entirely different strategy of tissue engineering of the corneal epithelium and other tissues will be at hand in the future.

\section{Acknowledgment}

This work is supported by grants RO1 EY06819 and RO1 EY015735 (to SCGT) from National Eye Institute, National Institutes of Health, Bethesda, Maryland, USA.

\section{References}

1 Schermer A, Galvin S, Sun TT. Differentiation-related expression of a major $64 \mathrm{~K}$ corneal keratin in vivo and in culture suggests limbal location of corneal epithelial stem cells. J Cell Biol 1986; 103:49-62.

2 Kruse FE, Chen JJY, Tsai RJF, Tseng SCG. Conjunctival transdifferentiation is due to the incomplete removal of limbal basal epithelium. Invest Ophthalmol Vis Sci 1990; 31:1903-1913.

3 Puangsricharern V, Tseng SCG. Cytologic evidence of corneal diseases with limbal stem cell deficiency. Ophthalmology 1995; 102:1476-1485

4 Kenyon KR, Tseng SC. Limbal autograft transplantation for ocular surface disorders. Ophthalmology 1989; 96:709-722.

5 Romano AC, Espana EM, Yoo SH, Budak MT, Wolosin JM, Tseng SC. Different cell sizes in human limbal and central corneal basal epithelia measured by confocal microscopy and flow cytometry. Invest Ophthalmol Vis Sci 2003; 44:5125-5129.

6 Cotsarelis G, Cheng SZ, Dong G, Sun TT, Lavker RM. Existence of slow-cycling limbal epithelial basal cells that can be preferentially stimulated to proliferate:implications on epithelial stem cells. Cell 1989; 57:201-209.

7 Kurpakus MA, Maniaci MT, Esco M. Expression of keratins K12, K4, and K14 during development of ocular surface epithelium. Curr Eye Res 1994; 13:805-814.

8 Liu CY, Zhu G, Converse R, et al. Characterization and chromosomal localization of the cornea-specific murine keratin gene Krt1.12. J Biol Chem 1994; 260:24627-24636.

9 Chen WY, Mui MM, Kao WW, Liu CY, Tseng SC. Conjunctival epithelial cells do not transdifferentiate in organotypic cultures: expression of K12 keratin is restricted to corneal epithelium. Curr Eye Res 1994; 13:765-778.

10 Chen Z, de Paiva CS, Luo L, Kretzer FL, Pflugfelder SC, Li DQ. Characterization of putative stem cell phenotype in human limbal epithelia. Stem Cells 2004; 22:355-366.

11 Matic M, Petrov IN, Chen S, Wang C, Dimitrijevich SD, Wolosin JM. Stem cells of the corneal epithelium lack connexins and metabolite transfer capacity. Differentiation 1997; 61:251-260.

12 Ebato B, Friend J, Thoft RA. Comparison of central and peripheral human corneal epithelium in tissue culture. Invest Ophthalmol Vis Sci 1987; 28:1450-1456.

13 Kruse FE, Tseng SCG. A tumor promoter-resistant subpopulation of progenitor cells is present in limbal epithelium more than corneal epithelium. Invest Ophthalmol Vis Sci 1993; 34:25012511.

14 Lindberg K, Brown ME, Chaves HV, Kenyon KR, Rheinwald JG. In vitro preparation of human ocular surface epithelial cells for transplantation. Invest Ophthalmol Vis Sci 1993; 34:26722679.

15 Pellegrini G, Golisano O, Paterna P, et al. Location and clonal analysis of stem cells and their differentiated progeny in the human ocular surface. J Cell Biol 1999; 145:769-782.

16 Lavker RM, Wei ZG, Sun TT. Phorbol ester preferentially stimulates mouse fornical conjunctival and limbal epithelial cells to proliferate in vivo. Invest Ophthalmol Vis Sci 1998; 39:301307.

17 Hernandez Galindo EE, Theiss C, Steuhl KP, Meller D. Expression of Delta Np63 in response to phorbol ester in human limbal epithelial cells expanded on intact human amniotic membrane. Invest Ophthalmol Vis Sci 2003; 44:2959-2965.

18 Kasper M. Patterns of cytokeratins and vimentin in guinea pig and mouse eye tissue:evidence for regional variations in intermediate filament expression in limbal epithelium. Acta Histochem 1992; 93:319-332.

19 Stepp MA, Zhu L, Sheppard D, Cranfill R. Localized distribution of alpha 9 integrin in the cornea and changes in expression during corneal epithelial cell differentiation. J Histochem Cytochem 1995; 43:353-362.

20 Pellegrini G, Dellambra E, Golisano O, et al. p63 identifies keratinocyte stem cells. Proc Natl Acad Sci U S A 2001; 98:3156- 
3161.

21 Di Iorio E., Barbaro V, Ruzza A, Ponzin D, Pellegrini G, De Luca M. Isoforms of DeltaNp63 and the migration of ocular limbal cells in human corneal regeneration. Proc Natl Acad Sci U S A 2005; 102:9523-9528.

22 Kawasaki S, Tanioka H, Yamasaki K, Connon CJ, Kinoshita S. Expression and tissue distribution of p63 isoforms in human ocular surface epithelia. Exp Eye Res 2005; 82:293-299.

23 Watanabe K, Nishida K, Yamato M, et al. Human limbal epithelium contains side population cells expressing the ATP-binding cassette transporter ABCG2. FEBS Lett 2004; 565:6-10.

24 Budak MT, Alpdogan OS, Zhou M, Lavker RM, Akinci MA, Wolosin JM. Ocular surface epithelia contain ABCG2-dependent side population cells exhibiting features associated with stem cells. J Cell Sci 2005; 118:1715-1724.

25 De Paiva CS, Chen Z, Corrales RM, Pflugfelder S, Li DQ. ABCG2 transporter identifies a population of clonogenic human limbal epithelial cells. Stem Cells 2005; 23:63-73.

26 Hayashi R, Yamato M, Sugiyama H, et al. N-cadherin is expressed by putative stem/progenitor cells and melanocytes in the human limbal epithelial stem cell niche. Stem Cells 2006; Sep 28. Epub ahead of print.

27 Tsai RJF, Sun TT, Tseng SCG. Comparison of limbal and conjunctival autograft transplantation for corneal surface reconstruction in rabbits. Ophthalmology 1990; 97:446-455.

28 Tsai RJF, Tseng SCG. Effect of stromal inflammation on the outcome of limbal transplantation for corneal surface reconstruction. Cornea 1995; 14:439-449.

29 Yao YF, Inoue Y, Miyazaki D, Shimomura Y, Ohashi Y, Tano Y. Ocular resurfacing and alloepithelial rejection in a murine keratoepithelioplasty model. Invest Ophthalmol Vis Sci 1995; 36:2623-2633.

30 Tsai RJF, Tseng SCG. Human allograft limbal transplantation for corneal surface reconstruction. Cornea 1994; 13:389-400.

31 Holland EJ. Epithelial transplantation for the management of severe ocular surface disease. Trans Am Ophthalmol Soc 1996; 94:677-743.

32 Tsubota K, Satake Y, Kaido M, et al. Treatment of severe ocular surface disorders with corneal epithelial stem-cell transplantation. N Eng J Med 1999; 340:1697-1703.

33 Pellegrini G, Traverso CE, Franzi AT, Zingirian M, Cancedda R, de Luca M. Long-term restoration of damaged corneal surface with autologous cultivated corneal epithelium. Lancet 1997; 349:990-993.

34 Tsai RJF, Li LM, Chen JK. Reconstruction of damaged corneas by transplantation of autologous limbal epithelial cells. N Eng J Med 2000; 343:86-93.

35 Tseng SCG. Concept and application of limbal stem cells. Eye 1989; 3:141-157.

36 Wolosin JM, Xiong X, Schütte M, Stegman Z, Tieng A. Stem cells and differentiation stages in the limbo-corneal epithelium. Prog Retinal \& Eye Res 2000; 19:223-255.

37 Dua HS, Azuara-Blanco A. Limbal stem cells of the corneal epithelium. Surv Ophthalmol 2000; 44:415-425.

38 Dua HS, Joseph A, Shanmuganathan VA, Jones RE. Stem cell differentiation and the effects of deficiency. Eye 2003; 17:877885 .

39 Grueterich M, Espana EM, Tseng SCG. Ex vivo expansion of limbal epithelial stem cells:Amniotic membrane serving as a stem cell niche. Surv Ophthalmol 2003; 48:631-646.

40 Ramaesh K, Dhillon B. Ex vivo expansion of corneal limbal epithelial/stem cells for corneal surface reconstruction. Eur J Ophthalmol 2003; 13:515-524.

41 Lavker RM, Tseng SC, Sun TT. Corneal epithelial stem cells at the limbus:looking at some old problems from a new angle. Exp Eye Res 2004; 78:433-446.

42 Wolosin JM, Budak MT, Akinci MA. Ocular surface epithelia and stem cell development. Int J Dev Biol 2004; 48:981-991.

43 Sun TT, Lavker RM. Corneal epithelial stem cells:past, present, and future. J Investig Dermatol Symp Proc 2004; 9:202-207.

44 Schlotzer-Schrehardt U, Kruse FE. Identification and characterization of limbal stem cells. Exp Eye Res 2005; 81:247-264.

45 Wolosin JM. Cell markers and the side population phenotype in ocular surface epithelial stem cell characterization and isolation. Ocular Surface J 2006; 4:10-23.

46 Fuchs E, Tumbar T, Guasch G. Socializing with the neighbors: stem cells and their niche. Cell 2004; 116:769-778.

47 Moore KA, Lemischka IR. Stem cells and their niches. Science 2006; 311:1880-1885.

$48 \mathrm{Li} \mathrm{L}$, Xie T. Stem cell niche:structure and function. Annu Rev Cell Dev Biol 2005; 21:605-631.

49 Davanger M, Evensen A. Role of the pericorneal papillary structure in renewal of corneal epithelium. Nature 1971; 229:560561.

50 Coroneo MT, Muller-Stolzenburg NW, Ho A. Peripheral light focusing by the anterior eye and the ophthalmohelioses. Ophthalmic Surg 1991; 22:705-711.

51 Higa K, Shimmura S, Miyashida H, Shimazaki J, Tsubota K. Melanocytes in the corneal limbus interact with K19-positive basal epithelial cells. Exp Eye Res 2005; 81:218-223.

52 Baum JL. Melanocyte and Langerhans cell population of the cornea and limbus in the albino animal. Am J Ophthalmol 1970; 69:669-676.

53 Vantrappen L, Geboes K, Missotten L, Maudgal PC, Desmet V. Lymphocytes and Langerhans cells in the normal human cornea. Invest Ophthalmol Vis Sci 1985; 26:220-225.

54 Gipson IK. The epithelial basement membrane zone of the limbus. Eye 1989; 3:132-140.

55 Dua HS, Shanmuganathan VA, Powell-Richards A, Tiqhe PJ, Joseph A. Limbal epithelial crypts:a novel anatomical structure and a putative limbal stem cell niche. Br J Ophthalmol 2005; 89:529-532.

56 Shanmuganathan VA, Foster T, Kulkarni BB, Hopkinson A, Gray T, Powe DG, Lowe J, Dua HS. Morphological Characteristics of the Limbal Epithelial Crypt. Br J Ophthalmol 2006; 2006 Oct 4; Epub ahead of print .

57 Tuori A, Uusitalo H, Burgeson RE, Terttunen J, Virtanen I. The immunohistochemical composition of the human corneal basement membrane. Cornea 1996; 15:286-294.

58 Ljubimov AV, Burgeson RE, Butkowski RJ, Michael AF, Sun T-T, Kenney MC. Human corneal basement membrane heterogeneitiy: topographical differences in the expression of type IV collagen and laminin isoforms. Lab Invest 1995; 72:461-473.

59 Kedinger M, Lefebvre O, Duluc I, Freund JN, Simon-Assmann P. Cellular and molecular partners involved in gut morphogenesis and differentiation. Philos Trans R Soc Lond B Biol Sci 1998; 353:847-856.

60 Quesenberry PJ, Becker PS. Stem cell homing:rolling, crawling, 
and nesting. Proc Natl Acad Sci U S A 1998; 95:15155-15157.

61 Peifer M. Signal transduction. Neither straight nor narrow. Nature 1999; 400:213-215.

62 Lawrenson JG, Ruskell GL. The structure of corpuscular nerve endings in the limbal conjunctiva of the human eye. J Anat 1991; 177:75-84

63 Goldberg MF, Bron AJ. Limbal palisades of Vogt. Trans Am Ophthalmol Soc 1982; 80:155-171.

64 Nakamura T, Ishikawa F, Sonoda KH, Hisatomi T, Qiao H, Yamada J, Fukata M, Ishibashi T, Harada M, Kinoshita S. Characterization and distribution of bone marrow-derived cells in mouse cornea. Invest Ophthalmol Vis Sci 2005; 46:497-503.

65 Narisawa Y, Kohda H, Tanaka T. Three-dimensional demonstration of melanocyte distribution of human hair follicles:special reference to the bulge area. Acta Derm Venereol 1997; 77:97101.

66 Espana EM, Kawakita T, Romano A, Di Pascuale M, Smiddy R, Liu CY, Tseng SC. Stromal niche controls the plasticity of limbal and corneal epithelial differentiation in a rabbit model of recombined tissue. Invest Ophthalmol Vis Sci 2003; 44:51305135.

67 Kawakita T, Espana EM, He H, Li W, Tseng SCG. Intrastromal invasion by limbal epithelial progenitor cells is mediated by epithelial-mesenchymal transition activated by air exposure. Am J Pathol 2005; 167:381-393.

68 Ferraris C, Chaloin-Dufau C, Dhouailly D. Transdifferentiation of embryonic and postnatal rabbit corneal epithelial cells. Differentiation 1994; 57:89-96.

69 Ferraris C, Chevalier G, Favier B, Jahoda CA, Dhouailly D. Adult corneal epithelium basal cells possess the capacity to activate epidermal, pilosebaceous and sweat gland genetic programs in response to embryonic dermal stimuli. Development 2000; 127:5487-5495.

70 Pearton DJ, Yang Y, Dhouailly D. Transdifferentiation of corneal epithelium into epidermis occurs by means of a multistep process triggered by dermal developmental signals. Proc Natl Acad Sci U S A 2005; 102:3714-3719.

71 Tumbar T, Guasch G, Greco V, Blanpain C, Lowry WE, Rendl M, Fuchs E. Defining the epithelial stem cell niche in skin. Science 2004; 303:359-363.

72 Urbanek K, Cesselli D, Rota M, Nascimbene A, De AA, Hosoda T, Bearzi C, Boni A, Bolli R, Kajstura J, Anversa P, Leri A. Stem cell niches in the adult mouse heart. Proc Natl Acad Sci U S A 2006; 103:9226-9231.

73 Morris RJ, Liu Y, Marles L, Yang Z, Trempus C, Li S, Lin JS, Sawicki JA, Cotsarelis G. Capturing and profiling adult hair follicle stem cells. Nat Biotechnol 2004; 22:411-417.

74 Collinson JM, Morris L, Reid AI, et al. Clonal analysis of patterns of growth, stem cell activity, and cell movement during the development and maintenance of the murine corneal epithelium. Dev Dyn 2002; 224:432-440.

75 Espana EM, Romano AC, Kawakita T, Di Pascuale M, Smiddy $\mathrm{R}$, Tseng SC. Novel enzymatic isolation of an entire viable human limbal epithelial sheet. Invest Ophthalmol Vis Sci 2003; 44:4275-4281.

76 Kawakita T, Espana EM, He H, Yeh LK, Liu CY, Tseng SCG. Epidermal differentiation promoted by high calcium serum free condition in mouse corneal/limbal epithelial culture. Invest Ophthalmol Vis Sci 2005; 45:3507-3512.
77 Goodell MA, Brose K, Paradis G, Conner AS, Mulligan RC. Isolation and functional properties of murine hematopoietic stem cells that are replicating in vivo. J Exp Med 1996; 183:17971806.

78 Goodell MA, Rosenzweig M, Kim H, et al. Dye efflux studies suggest that hematopoietic stem cells expressing low or undetectable levels of CD34 antigen exist in multiple species. Nat Med 1997; 3:1337-1345.

79 Zhou S, Schuetz JD, Bunting KD, et al. The ABC transporter Bcrp1/ABCG2 is expressed in a wide variety of stem cells and is a molecular determinant of the side-population phenotype. Nat Med 2001; 7:1028-1034.

80 Umemoto T, Yamato M, Nishida K, et al. Rat limbal epithelial side population cells exhibit a distinct expression of stem cell markers that are lacking in side population cells from the central cornea. FEBS Lett 2005; 579:6569-6574.

81 Umemoto T, Yamato M, Nishida K, Yang J, Tano Y, Okano T. Limbal epithelial side-population cells have stem cell-like properties, including quiescent state. Stem Cells 2006; 24:86-94.

82 Park KS, Lim CH, Min BM, et al. The side population cells in the rabbit limbus sensitively increased in response to the central cornea wounding. Invest Ophthalmol Vis Sci 2006; 47:892900.

83 Redvers RP, Li A, Kaur P. Side population in adult murine epidermis exhibits phenotypic and functional characteristics of keratinocyte stem cells. Proc Natl Acad Sci U S A 2006; 103:13168-13173.

84 Wolosin JM, Akinci MA, Taveras M, Turner H. Intraepithelial lymphocytes are a major component of ocular surface epithelial side populations. 2006. In principle.

85 Rheinwald JG, Green H. Serial cultivation of strains of human epidermal keratinocytes:the formation of keratinizing colonies from single cells. Cell 1975; 6:331-337.

86 Larderet G, Fortunel NO, Vaigot P, et al. Human side population keratinocytes exhibit long-term proliferative potential and a specific gene expression profile and can form a pluristratified epidermis. Stem Cells 2006; 24:965-974.

87 Koizumi N, Inatomi T, Quantock AJ, Fullwood NJ, Dota A, Kinoshita S. Amniotic membrane as a substrate for cultivating limbal corneal epithelial cells for autologous transplantation in rabbits. Cornea 2000; 19:65-71.

88 Meller D, Pires RTF, Tseng SCG. Ex vivo preservation and expansion of human limbal epithelial stem cells on amniotic membrane cultures. Br J Ophthalmol 2002; 86:463-471.

89 Grueterich M, Tseng SCG. Human limbal progenitor cells expanded on intact amniotic membrane. Arch Ophthalmol 2002; 120:783-790.

90 Tseng SCG, Kim JC, Meller D, et al. Amniotic membrane transplantation for ocular surface reconstruction. Hong Kong J Ophthalmol 1998; 2:26-34.

91 Kruse FE, Joussen AM, Rohrschneider K, et al. Cryopreserved human amniotic membrane for ocular surface reconstruction. Graefe's Arch Clin Exp Ophthalmol 2000; 238:68-75.

92 Sippel KC, Ma JJK, Foster CS. Amniotic membrane surgery. Curr Opin Ophthalmol 2001; 12:269-281.

93 Dua HS, Gomes JA, King AJ, Maharajan VS. The amniotic membrane in ophthalmology. Surv Ophthalmol 2004; 49:51-77.

94 Bouchard CS, John T. Amniotic Membrane Transplantation in the Management of Severe Ocular Surface Disease:Indications 
and Outcomes. The Ocular Surface 2004; 2:201-211.

95 Tseng SCG, Espana EM, Kawakita T, et al. How does amniotic membrane work? The Ocular Surface 2004; 2:177-187.

96 Anderson DF, Ellies P, Pires RT, Tseng SC. Amniotic membrane transplantation for partial limbal stem cell deficiency. Br J Ophthalmol 2001; 85:567-575.

97 Gomes JA, dos Santos MS, Cunha MC, Mascaro VL, Barros JN, de Sousa LB. Amniotic membrane transplantation for partial and total limbal stem cell deficiency secondary to chemical burn. Ophthalmology 2003; 110:466-473.

98 Sangwan VS, Matalia HP, Vemuganti GK, Rao GN. Amniotic membrane transplantation for reconstruction of corneal epithelial surface in cases of partial limbal stem cell deficiency. Indian J Ophthalmol 2004; 52:281-285.

99 Grueterich M, Espana EM, Touhami A, Ti SE, Tseng SC. Phenotypic study of a case with successful transplantation of ex vivo expanded human limbal epithelium for unilateral total limbal stem cell deficiency. Ophthalmology 2002; 109:1547-1552.

100Sangwan VS, Vemuganti GK, Singh S, Balasubramanian D. Successful reconstruction of damaged ocular outer surface in humans using limbal and conjuctival stem cell culture methods. Biosci Rep 2003; 23:169-174.

101 Grueterich M, Espana E, Tseng SC. Connexin 43 expression and proliferation of human limbal epithelium on intact and denuded amniotic membrane. Invest Ophthalmol Vis Sci 2002; 43:6371.

102 Whetton AD, Graham GJ. Homing and mobilization in the stem cell niche. Trends Cell Biol 1999; 9:233-238.

103 Kai T, Spradling A. An empty Drosophila stem cell niche reactivates the proliferation of ectopic cells. Proc Natl Acad Sci U S A $2003 ; \mathbf{1 0 0}: 4633-4638$.

104Dua HS, Jagjit SS, Azuara-Blanco A, Gupta P. Limbal stem cell deficiency:concept, aetiology, clinical presentation, diagnosis and management. Indian J Ophthalmol 2000; 48:83-92.

105Ramaesh T, Ramaesh K, Martin CJ, Chanas SA, Dhillon B, West JD. Developmental and cellular factors underlying corneal epithelial dysgenesis in the Pax6+/- mouse model of aniridia. Exp Eye Res 2005; 81:224-235.

106Ramaesh K, Ramaesh T, Dutton GN, Dhillon B. Evolving concepts on the pathogenic mechanisms of aniridia related keratopathy. Int J Biochem Cell Biol 2005; 37:547-557.

107Espana EM, Di Pascuale MA, He H, et al. Characterization of corneal pannus removed from patients with total limbal stem cell deficiency. Invest Ophthalmol Vis Sci 2004; 45:2961-2966.

108Li W, Hayashita Y, He H, Kuo CL, Tseng SCG. The fate of limbal epithelial progenitor cells during explant culture on intact amniotic membrane. In press.

109Kalluri R, Neilson EG. Epithelial-mesenchymal transition and its implications for fibrosis. J Clin Invest 2003; 112:1776-1784.

110 Cvekl A, Tamm ER. Anterior eye development and ocular mesenchyme:new insights from mouse models and human diseases. BioEssays 2004; 26:374-386.

111 Green H, Easley K, Iuchi S. Marker succession during the devel- opment of keratinocytes from cultured human embryonic stem cells. Proc Natl Acad Sci U S A 2003; 100:15625-15630.

112 Li HS, Yang JM, Jacobson RD, Pasko D, Sundin O. Pax-6 is first expressed in a region of ectoderm anterior to the early neural plate:implications for stepwise determination of the lens. Dev Biol 1994; 162:181-194.

113 Koroma BM, Yang JM, Sundin OH. The Pax-6 homeobox gene is expressed throughout the corneal and conjunctival epithelia. Invest Ophthalmol Vis Sci 1997; 38:108-120.

114 Jamieson RV, Perveen R, Kerr B, et al. Domain disruption and mutation of the bZIP transcription factor, MAF, associated with cataract, ocular anterior segment dysgenesis and coloboma. Hum Mol Genet 2002; 11:33-42.

115 Ormestad M, Blixt A, Churchill A, Martinsson T, Enerback S, Carlsson P. Foxe3 haploinsufficiency in mice:a model for Peters' anomaly. Invest Ophthalmol Vis Sci 2002; 43:1350-1357.

116 Semina EV, Ferrell RE, Mintz-Hittner HA, et al. A novel homeobox gene PITX3 is mutated in families with autosomal-dominant cataracts and ASMD. Nat Genet 1998; 19:167-170.

117Chung EH, Bukusoglu G, Zieske JD. Localization of corneal epithelial stem cells in the developing rat. Invest Ophthalmol Vis Sci 1992; 33:2199-2206.

118 Zieske JD, Wasson M. Regional variation in distribution of EGF receptor in developing and adult corneal epithelium. J Cell Sci 1993; 106:145-152.

119 Tseng H, Matsuzaki K, Lavker RM. Basonuclin in murine corneal and lens epithelia correlates with cellular maturation and proliferative ability. Differentiation 1999; 65:221-227.

120Mukhopadhyay M, Gorivodsky M, Shtrom S, et al. Dkk2 plays an essential role in the corneal fate of the ocular surface epithelium. Development 2006; 133:2149-2154.

121 Nicolas M, Wolfer A, Raj K, et al. Notch1 functions as a tumor suppressor in mouse skin. Nat Genet 2003; 33:416-421.

122Chang B, Smith RS, Peters M, et al. Haploinsufficient Bmp4 ocular phenotypes include anterior segment dysgenesis with elevated intraocular pressure. BMC Genet 2001; 2:18.

123 Lovicu FJ, Kao WW, Overbeek PA. Ectopic gland induction by lens-specific expression of keratinocyte growth factor (FGF-7) in transgenic mice. Mech Dev 1999; 88:43-53.

124Croft AP, Przyborski SA. Formation of neurons by non-neural adult stem cells:potential mechanism implicates an artifact of growth in culture. Stem Cells 2006; 24:1841-1851.

125Zhao X, Das AV, Thoreson WB, et al. Adult corneal limbal epithelium:a model for studying neural potential of non-neural stem cells/progenitors. Dev Biol 2002; 250:317-331.

126Seigel GM, Sun W, Salvi R, Campbell LM, Sullivan S, Reidy JJ. Human corneal stem cells display functional neuronal properties. Mol Vis 2003; 9:159-163.

127Espana EM, Romano AC, Kawakita T, Di Pascuale M, Smiddy $\mathrm{R}$, Tseng SC. Novel enzymatic isolation of an entire viable human limbal epithelial sheet. Invest Ophthalmol Vis Sci 2003; 44:4275-4281. 